УДК 902.02

https://doi.org/10.24852/2587-6112.2021.3.186.191

\title{
ПОЯСНОЙ НАБОР ИЗ ПОГРЕБЕНИЯ 6 МОГИЛЬНИКА «НИЖНЯЯ СТРЕЛКА» В СИСТЕМЕ КУЛЬТУРНЫХ СВЯЗЕЙ НАСЕЛЕНИЯ ВЕТЛУЖСКО-ВЯТСКОГО МЕЖДУРЕЧЬЯ
}

\author{
(C) 2021 г. Т.Б. Никитина
}

В статье представлен материал поясного набора (накладки - 3 типа, пряжки - 2 типа, наконечник) из погребения 6 марийского могильника «Нижняя Стрелка», на основании которого выполнена графическая реконструкция пояса. Представленный поясной набор является для Ветлужско-Вятского междуречья, на территории которого расположен могильник, необычным. Ближайшие аналогии накладкам всех типов в одном комплексе отмечены в кургане 18 Синеглазова субботцевского круга, а также в венгерских памятниках периода Арпадов. На основании приведенной в статье датировки комплекса (не позже середины X в.) и выявленных аналогий деталям поясной гарнитуры возможно предположить, что в Ветлужско-Вятском междуречье наблюдается сохранение пережитков постсубботцевского стиля, проникших в этот регион, возможно, и опосредовано, но от населения, непосредственно знакомого с субботцевскими традициями.

Ключевые слова: археология, Марийская культура эпохи средневековья, наборный пояс, постсубботцевский стиль, датировка.

\section{BELT SET FROM BURIAL 6 OF “NIZHNYAYA STRELKA" BURIAL GROUND IN THE SYSTEM OF CULTURAL RELATIONS OF THE POPULATION OF THE VETLUGA-VYATKA INTERFLUVE}

\section{T. B. Nikitina}

The paper features the material of a belt set (pads - 3 types, buckles -2 types, and a tip) from the burial 6 of "Nizhnyaya Strelka" Mari burial ground, which was used as a basis for a graphic reconstruction of the belt. The belt set is unusual for the Vetluga-Vyatka interfluve, where the burial ground is located. The closest analogies to the pads of all types in a single complex were discovered in barrow 18 of Sineglazovo site of the Subbottsevo circle, as well as in the Hungarian sites of the Arpad period. Based on the dating of the complex given in the article (not later than the mid- $10^{\text {th }}$ century) and the revealed analogies to the details of the belt set, it can be assumed that the Vetluga-Vyatka interfluve contains the remnants of the post-Subbottsevo style which penetrated into this region, possibly indirectly, from the population directly familiar with the Subbottsevo traditions

Keywords: archaeology, Mari culture of the Middle Ages, composite belt, post- Subbottsevo style, dating

В погребении 6 могильника «Нижняя стрелка обнаружен поясной набор, который на сегодняшний день не имеет аналогов в могильниках Ветлужско-Вятского междуречья.

Могильник «Нижняя стрелка» располагается на высокой дюне в левобережной пойме р. Волги, недалеко от д. Починок Юринского района. Памятник изучен полностью в 1987, 1988, 2007 гг. Т.Б. Никитиной.

Погребение 6 представляет собой кенотаф (Никитина, 1987, рис. 63; Никитина, 2012, c. 36 , рис. 144). На глубине 25 см сразу под слоем дерна обнаружены фрагменты сосуда с уплощенным дном. Керамика слабого обжига, поэтому сохранность очень плохая. Под сосудом заметно слабое светло-серое заполнение неопределенных очертаний. Более четкие границы обозначились лишь на глубине 75 см. Могильное заполнение овальной формы размерами $170 Ч 50$ см длинной стороной ориентировано по линии ССЗ - ЮВВ. В засыпи могильной ямы зафиксированы крупные куски угля. Вещи лежали на глубине 75 см на подстилке из луба, сверху закрыты досками. Костей в погребении не обнаружено. Вещи разложены с С на Ю в порядке их расположения при ингумации, украшения соответствуют месту в костюме.

Инвентарь. В северной стороне лежало два серебряных височных кольца с отогнутым концом (№ 1) (рис. 1: 1), в области рук - два бронзовых граненных браслета с кружковым орнаментом на гранях (№ 2, 2a) (рис. 1: 2, 2a), чуть ниже - кожаный ремень с пряжками, металлическими накладками и наконечником (№ 3) (рис. 1: 3), железный нож (№ 4) (рис. 1: 4) в железных ножнах с войлочной прокладкой изнутри. В южном углу могилы обнаружены 


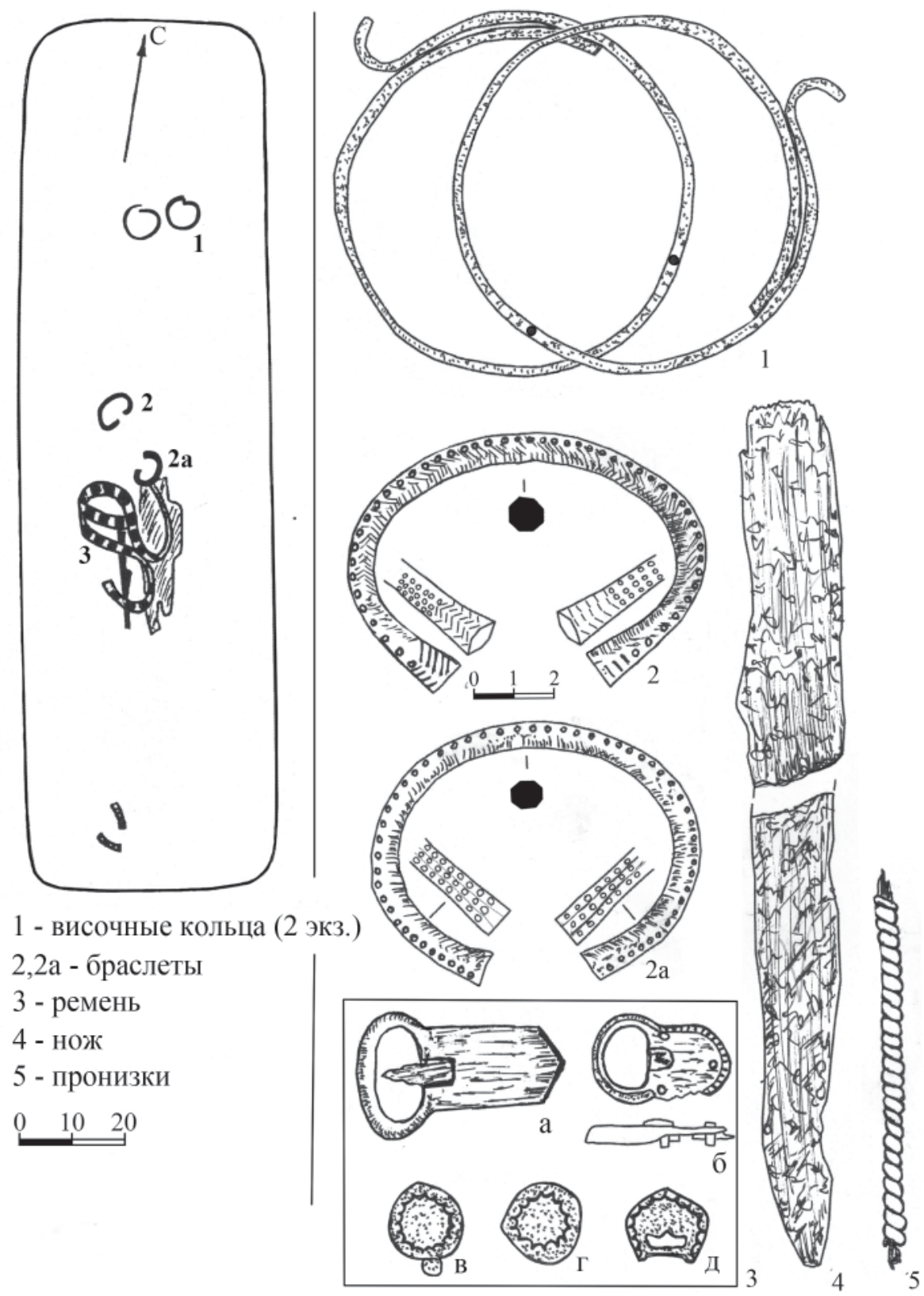

Рис. 1. Могильник «Нижняя стрелка», погребение 1. 1-3 - цветной металл; 4 - железо; 5 - кожа, цветной металл Fig. 1. Burial ground "Nizhnyaya Strelka", interment 1.1-3 - non-ferrous metal; 4 - iron; 5 - leather, non-ferrous metal

бронзовые пронизки из плоской витой проволоки на кожаном ремешке (№ 5) (рис. 1: 5).

Расположение пояса, как и иных украшений в кенотафе, символично, но хорошая сохранность кожи и составных деталей позволяет сделать реконструкцию. Пояс находился в центре могилы, условно в области талии. К нему крепился нож.

Основу пояса составлял ремень из кожаной ленты шириной 1,6 см (рис. 2: 1). Длина ремня с накладками около 128 см, один конец завершается пряжкой, другой наконечником. Учитывая, что ширина наконечника превышает проем рамки пряжки, очевидно, что ремень застегивался с помощью вспомогательного ремешка, который не имел накладок и наконеч- ника. Судя по длине, ремень мог быть обернут вокруг корпуса человека в 1 оборот, спереди длинный конец был перекинут через ремень с левой стороны на правую, образуя дополнительный ряд, и свободный конец с наконечником опущен вниз. Задняя часть ремня и небольшой фрагмент с правой стороны перед пряжкой украшены пятиугольными накладками. Сзади с обеих сторон от пятиугольных накладок крепились сердцевидные накладки с круглой головкой на нижнем крае. Передняя часть и опущенный вниз конец имели сердцевидные накладки, прикрепленные мысиком вдоль ремня. Накладки крепились с помощью шпеньков, пронизывающих кожу и загнутых с изнаночной стороны. Набор характеризуется 




Рис. 2.1 - реконструкция пояса из погребения 6 могильника «Нижняя стрелка»; 2,6 - пряжки, 3-5 - накладки, 7 - конец ремня. 1, 2, 4, 7 - кожа, цветной металл; 3,5 - цветной металл; 6 - цветной металл, железо

Fig. 2. 1 - reconstruction of the belt from the interment 6 of the burial ground "Nizhnyaya Strelka"; 2,6 - buckles, 3-5pads, 7 - the end of the belt. 1,2, 4, 7 - leather, non-ferrous metal; 3,5-non-ferrous metal; 6-non-ferrous metal, iron

наличием 2-х пряжек и 3-х типов накладок, оформленных в одном стиле.

1. Накладки сердцевидной формы с плавными очертаниями и головкой с нижней стороны имели размеры 2,0Ч1,7 см, крепились по ширине накладки двумя шпеньками (рис. 2: 3), загнутыми с обратной стороны. На поверхности по контуру изделия заметен бордюр.

2. Накладки сердцевидной формы плавными очертаниями без головки имели размеры 1,8Ч1,6 см, бордюр по контуру и два шпенька для крепления, расположенные по центральной оси накладки (рис. 2: 5).

3. Пятиугольные накладки с бордюром по контуру и прорезью у основания имели разме-

ры 1,5Ч1,7 см и два шпенька для крепления по ширине изделия (рис. 2: 4).

4. Наконечник размерами 7,0Ч1,8 см имеет прямые параллельные стороны, закругленный конец и фигурный противоположный край, насечки по бордюру; крепился с помощью 4-х загнутых с обратной стороны шпеньков (рис. 2: 7).

5. Пряжка овальнорамчатая имеет длину 4,0 cм, ширину рамки $-2,5$ см, ширину щитка - 1,6 см; неподвижный вытянутый пятиугольный щиток и железный язычок (рис. 2: 8).

6. Пряжка овальнорамчатая размерами 3,0Ч1,5/1,7 см с небольшим щитком геральдической формы с изображением трилистника имеет железный язычок (рис. 2: 9). 
Ближайшие аналогии накладкам всех типов в одном комплексе отмечены в кургане 18 Синеглазова субботцевского круга (Боталов, 1987, рис. 2: 10; Комар, 2018, рис. 66: 15), а также в венгерских памятниках периода Арпадов: Тисаседеркень, п. 2 (The Ancient..., 1996, с. 414), Тисаэзлар-Басхалом (The Ancient..., 1996, c. 185), Tiszabezded-Haranglab-dülo (Eszter, 2003, tab. 202), накладки серцевидные и с головкой находились в одном поясном наборе в погребении Вереба (Комар, 2018, с. 415, рис. 99: 6; Hampel, 1905; The Ancient..., 1996 , с. 375).

Датировка погребения имеет определенные трудности. Инвентарь небогат, и основополагающими для выводов являются составные части поясного набора.

Пряжка с пятиугольным щитком имеет сходство с изделиями из других погребений Ветлужско-Вятского междуречья: п. 5 Веселовского, п. 10 «Нижняя стрелка», п. 52 Дубовского (Никитина, 2012, рис. 147: 8; 257: 33). Погребение 52 Дубовского могильника датировано по монетам не ранее 920 -х гг. и не позднее конца 950-х гг, вещи также соответствуют этой дате (Никитина, 2012, с. 69, 70). Погребение 5 Веселовского могильника имеет более ранний облик: конец IX - начало X вв. Такая датировка основана на серии находок. В п. 5 Веселовского (кол. НГИАМЗ, № 12204) могильника присутствуют пятиугольные накладки небольших размеров, имеющие плохую сохранность, что зависит от состава металла (анализ, к сожалению, не проводился), аналогичные изделиям из пп. 1, 3-5 Кочергинского могильника (Талицкий, 1940, табл. III: 24; IV: 48; V: 64) н наибольшее сходство обнаруживающие с накладками из п. 175 Крюково-Кужновского могильника (Зеленцова, рукопись ${ }^{1}$ ), отнесенного к стадии 10, включающей погребения второй половины VIII - IX вв. (Вихляев, Беговаткин, и др., 2008, с. 144), и из п. 10 могильника Мыдлань-Шай (Генинг, 1962, с. 15, табл. IV: 15) с монетами VIII в. (полудрахма и монетовидные подвески оттиски с о. с. драхм времени Хосро) (Янина, 1962, с. 136), а также с накладками из Варнинского могильника (Семенов, 1980, табл. XIII: 11), п. 68 Большетиганского могильника, захоронений Тарского могильника на Кавказе (Комар, 2018, рис. 41: 9) горизонта III салтовских древностей в пределах IX в. и в погребениях Танкеевского могильника IV этапа развития (Комар, 2018, с. 154, 367). В п. 5 Веселовского могильника обнаружены 2 типа накладок пятиугольных очертаний со сглаженными контурами с тремя шаровидными выступами по углам фигуры (Никитина, 2012, рис. 21: 10, 11). Аналогичные изделия обнаружены также в п. 825 Танкеевского могильника (Khalikova-Kazakov, 1977, c. 199, pl. XXV: 5, 7), отнесенного к IV этапу (Комар, 2018, рис. 51). Погребение 10 Нижней стрелки имеет браслет с расширенными раздвоенными концами, завернутыми в трубочку, в которые продеты подвижные колечки (Вихляев, Беговаткин и др., 2008, рис. 65: 6). Находка в финно-угорских древностях достаточно редкая, но встречена в п. 12p Пановского могильника с достаточно широко распространенным типом сюльгамы $154 a$, имеющим аналогии преимущественно в памятниках конца VIII - середины IX вв. (Вихляев, Беговаткин и др., 2008, с. 53, 54) и в исключительных случаях в более поздний период. Два граненных массивных браслета с кружковым орнаментом также имеют достаточно ранний облик. В Варнинском могильнике поломской культуры подобные изделия характерны для чепецкой стадии и датируются второй половиной IX - Х вв. (Семенов, 1980, с. 64, табл. II: 33, 34).

Аналогии пряжке с пятиугольным щитком встречены в Танкеевском могильнике (Khalikova, Kazakov, 1977, c. 186, pl. XII: 15).

Курган 18 Синеглазова с накладками такого типа С.Г. Боталов датирует рубежом IX-X вв. (Боталов, 1988, с. 129). На сходство оформления накладок из п. 6 «Нижней стрелки» с изделиями субботцевского стиля обратил внимание А. Комар (Комар, 2018, с. 227). Пряжка малых размеров с геральдическим щитком позволила предполагать более поздний облик данного погребения. Немногочисленные аналогии на других территориях относятся ко второй половине X в.: п. 406 Крюково-Кужновского могильника стадии 11, материалы средневековых кочевников (Иванов, Крыласова, 2006, рис. $6,8)$, огузские погребения Верхне-Погромное (Комар, 2018, с. 222, 223, рис. 89: 6).

Но следует отметить, что в памятниках Ветлужско-Вятского междуречья пряжки такого типа являются достаточно частыми находками: пп. 46, 58, 60, 64 Дубовского могильника, пп. 29, 30, жк 8, 10 «Нижней стрелки», жк 11 Русенихинского могильника (Никитина, 2012, рис. 105: 10; 2018, рис. 61: 11). Большинство подобных пряжек датируются не ранее второй половины Х в. и позже: п. 60 Дубовского по монете Бувейхидов 338-363 гг. х. (949-974 гг.), п. 58 Дубовского по бусам и наконечнику (Никитина, 2012, с. 71), жк 8 Нижней стрелки по браслету (Никитина, 2012, с. 67), п. 11 Русенихинского по 
оттиску с подражания саманидским дирхемам 351 г. х. (962 гг.) (Мухаметшин, Гомзин, 2018, с. 244). Нельзя абсолютно исключать возможность появления таких пряжек и в более ранний период. Во всяком случае в п. 46 Дубовского могильника обнаружена монета и подражание династии Саманидов 301-331 г. х. (913/943) (Федоров-Давыдов, 1984, с. 151, 161).

В пользу датировки начала X в. свидетельствуют и другие находки из этого погребения.

На основании этого я склонна отнести п. 6 могильника «Нижняя стрелка» к X в., вернее всего, не позднее середины Х в.

Признавая распространение наборов «с практически идентичным оформлением поясных деталей... в Зауралье, Поволжье и Венгрии», А. Комар все же считает, что в данном случае это «свидетельствует не о дериватном статусе таких деталей, а о самостоятельном стиле, возникшем позже субботцевского горизонта» (Комар, 2018, с. 227).

Не исключая возможности возникновения нового стиля, похожего на существующий ранее, все же трудно согласиться с данным высказыванием. Нужно учитывать, что повторены не только форма и орнаментация изделий, но, что особенно важно, повторен состав поясного набора в целом с сохранением всех трех типов накладок. Мне кажется, что такой повтор возможен в том случае, если мастер сохранял в памяти увиденный когда-то образец. Или трудно поверить в абсолютное совпадение по комплектации изделий на такой широкой территории. Вполне возможно, что в Ветлужско-Вятском междуречье наблюдается сохранение пережитков постсубботцевского стиля, проникших в этот регион возможно и опосредовано, но от населения непосредственно знакомого с субботцевскими традициями.

\section{Примечание:}

${ }^{1}$ Автор выражает благодарность О.В. Зеленцовой за возможность использовать рукопись неопубликованного материала

\section{ЛИТЕРАТУРА}

Боталов С.Г. Курган у оз. Синеглазово (по раскопкам Н.К. Минко и С.А. Гатцука) // Ранний железный век и средневековье Урало-Иртышского междуречья / Отв. ред. Г.Б. Зданович. Челябинск: Челябинский государственный университет, 1986. С. 105-119.

Боталов С.Г. Культурно-хронологическая принадлежность Синеглазовских курганов // Проблемы археологии Урало-Казахстанских степей / Отв. ред. Г.Б.Зданович. Челябинск: Челябинский государственный университет, 1988. С. 126-140.

Вихляев В.И., Беговаткин А.А., Зеленцьова О.В., Шитов В.И. Хронология могильников населения I-XIV вв. западной части Среднего Поволжья / Научн. ред. И.М. Петербургский. Саранск: Республиканская типография «Красный октябрь», 2008. 352 с.

Генинг В.Ф. Мыдлань-Шай - удмуртский могильник VIII-IX вв. // Древнеудмуртский могильник Мыдлань-Шай / ВАУ. Вып. 3. / Отв. ред. В.Ф. Генинг. Свердловск. 1962. С. 7-112.

Иванов В.А., Крыласова Н.Б. Взаимодействие леса и степи Урало-Поволжья в эпоху средневековья (по материалам костюма). Пермь, 2006. 162 с.

Комар А. История и археология древних мадьяр в эпоху миграции. Budapest: Martin Opitz Kiadó, PPKEBTK Régészettudományi Intézet, MTABTK Magyar Östörtöneti Témacsoport, 2018. 424 c.

Мухаметиин, Д.Г., Гомзин А.А. Нумизматический материал из Русенихинского могильника //Археология Евразийских степей. 2018. №3. С. 242-255.

Никитина Т.Б. Погребальные памятники IX-XI вв. Ветлужско-Вятского междуречья // Археология Евразийских степей. Вып. 14. Казань: Отечество, 2012. 408 с.

Талицкий М.В. Кочергинский могильник // МИА. № 1 / Под ред. П.Н. Третьякова. М.-Л.: АН СССР, 1940. C. 159-168 c.

Шикаева Т.Б. Отчет о раскопках могильника Нижняя Стрелка в 1987 году / Архив ИА РАН, № 12585.

Федоров-Давыдов Г.А. Монеты из Дубовского могильника // Новые памятники археологии ВолгоКамья / АЭМК. Вып. 8 / Отв. ред. Г.А. Архипов. Йошкар-Ола: МАРНИИ, 1984. С. 160-172.

Eszter I. A Rétközhonfoglalás és Arpád-koriemlékanyaga / Régészeti gyüjtemények Nyíregyházán 2Nyiregyházan, 2003. 738 p.

Hampel J. Alterthümer des FrühenMittelalters in Ungarn. Braunschweig 1905.

Khalikova E.A., Kazakov E.P. Le cimetiere de Tankeevka // Les anciens hongrois et les ethnies voisines a 1'Est. Budapest, 1977. P. 21-221. 
The Ancient Hungarians. Exhibition Cataloque / Edited by Istvan Fodor. Budapest. 1996. 479 p.

\section{Информация об авторе:}

Никитина Татьяна Багишевна, доктор исторических наук, главный научный сотрудник, Марийский научно-исследовательский институт языка, литературы и истории им. В.М. Васильева (г. ЙошкарОла, Россия); tshikaeva@yandex.ru

\section{REFERENCES}

Botalov, S. F. 1986. In Zdanovich, G. B. (ed.). Rannii zheleznyi vek i srednevekov'e Uralo-Irtyshskogo mezhdurech'ia (Early Iron Age and Middle Ages in the Ural-Irtysh Interfluve). Chelyabinsk: Chelyabinsk State University, 105-119. (in Russian).

Botalov, S. F. 1988. In Zdanovich, G. B. (ed.). Problemy arkheologii Uralo-Kazahstanskikh stepei (Issues of the Archaeology of the Ural-Kazakhstan Steppes). Chelyabinsk: Chelyabinsk State University, 126-140 (in Russian).

Vikhliaev, V. I., Begovatkin, A. A., Zelentsova, O. V., Shitov, V. I. 2008. Khronologiia mogil'nikov naseleniia I-XIV vv. zapadnoi chasti Srednego Povolzh 'ia (Chronology of the Burial Grounds of $1^{\text {st }}-14^{\text {th }}$ Centuries in the Western Part of the Middle Volga Region). Saransk: "Krasnyi Oktiabr" Typography (in Russian).

Gening, V. F. 1962. In Gening, V. F. (ed.). Drevneudmurtskii mogil'nik Mydlan'-Shai (Mydlan-Shai Ancient Udmurt Burial Ground). Series: Voprosy arkheologii Urala (Issues of the Ural Archaeology) 3. Sverdlovsk, 7-112 (in Russian).

Ivanov, V. A., Krylasova, N. B. 2006. Vzaimodeistvie lesa i stepi Uralo-Povolzh'ia vepokhu srednevekov'ia (po materialam kostiuma)). (Interaction of the Forest and Steppe of the Ural-Volga Region in the Middle Ages (Based on Costume Materials)). Perm (in Russian).

Komar, A. 2018. Istorima i arkheologiia drevnikh mad'jar v epokhu migratsii (History and Archaeology of the Ancient Hungarians in the Era of Migration). Budapest: Martin Opitz Kiadó, PPKEBTK Régészettudományi Intézet, MTABTK Magyar Östörtöneti Témacsoport (in Russian).

Mukhametshin, D. G., Gomzin, A. A. 2018. In Arkheologiia Evraziiskikh stepei (Archaeology of Eurasian Steppes) 3, 242-255 (in Russian).

Nikitina, T. B. 2012. Pogrebal'nye pamiatniki IX-XI vv. Vetluzhsko-Viatskogo mezhdurech'ia (Burial Sites of the $9^{\text {th }}-11^{\text {th }}$ Centuries in the Vetluga-Vyatka Interfluvial Area). Series: Arkheologiya evraziiskikh stepei (Archaeology of Eurasian Steppes) 14. Kazan: "Otechestvo" Publ. (in Russian).

Shikaeva, T. B. Otchet o raskopkakh mogil'nika Nizhniaia Strelka $v 1987$ godu (Report on the Excavations of the Nizhnaya Strelka Burial Ground in 1987). Archive of the Institute of Archaeology of the Russian Academy of Sciences, dossier 12585 (in Russian).

Talitskiy, M. V. 1940. In Tretyakov P. N. (ed.). Materialy $i$ issledovaniia po arkheologii (Materials and Studies in the Archaeology) 1. Moscow-Leningrad: Academy of Sciences of the USSR, 159-168 (in Russian).

Fedorov-Davydov, G. A. 1984. In Arkhipov, G. A. (ed.). Novye pamiatniki arkheologii Volgo-Kam'ia (Recently Discovered Archaeological Sites in the Volga and Kama Rivers Area). Series: Arkheologiia i etnografiia Mariiskogo kraia (Archaeology and Ethnography of Mari Land) 8. Yoshkar-Ola: Mari Scientific and Research Language, Literature and History Institute, 160-172 (in Russian).

Eszter, I. 2003. A Rétközhonfoglalás és Arpád-koriemlékanyaga. Régészeti gyüjtemények Nyíregyházán 2. Nyiregyházan.

Hampel, J. 1905. Alterthümer des FrühenMittelalters in Ungarn. Braunschweig.

Khalikova, E. A., Kazakov, E. P. 1977. In Les anciens hongrois et les ethnies voisines a l'Est. Budapest. 21-221 (in French).

Fodor, I. 1996. (ed.). The Ancient Hungarians. Exhibition Cataloque.

\section{About the Author:}

Nikitina Tatyana B. Doctor of Historical Sciences. Mari El Language, Literature and History Research Institute named after V.M. Vasilyev. Krasnoarmeyskaya St., 44, Yoshkar-Ola, 424036, Mari El Republic, Russian Federation; tshikaeva@yandex.ru 